\title{
Processos artísticos conviviais e suas aproximações com o procedimento etnográfico ${ }^{1}$
}

\author{
Erika Ramos de Jesus Santana* \\ Maicyra Teles Leão e Silva* \\ Raul Henrique Araújo Santos ${ }^{* *}$ \\ Universidade Federal de Sergipe
}

\begin{abstract}
Resumo
0 presente artigo discute procedimentos artísticos de natureza convivial e sua aproximação com a etnografia contemporânea. Para isso, apresenta aspectos relacionados ao convívio enquanto poiesis realçando a busca pelo reconhecimento de alteridades. Nesse sentido, ao qualificar a etnografia como a própria motivação da antropologia, enquanto ciência do humano, ele destaca o confronto com o Outro como 0 articulador do conhecimento criativo. Assim, 0 artigo apresenta criticamente 0 projeto Olhar Forasteiro como experiência paupável da aproximação entre procedimento etnográfico e artístico.
\end{abstract}

Palavras-Chave

Convívio; Alteridade; Procedimento Artístico; Etnografia; Olhar Forasteiro.

Convivial artistic processes and their rapprochements with ethnographic procedures

Abstract

This article discusses convivial artistic procedures and its proximity to contemporary ethnography. For this, it presents aspects related to living together as poiesis, highlighting the quest for recognition of otherness. In this sense, to qualify ethnography as the very motivation of anthropology as a science of the human, it shows the confrontation with the Other as the articulator of creative knowledge. Thus, the article presents the project Foreigner View as an experience of rapprochement between ethnographic and artistic procedure.

\section{Keywords}

Conviviality; Alterity; Artistic Procedure; Ethnography; Foreigner View.

\footnotetext{
1 Este texto integra Pesquisa - PIBIC, em andamento, intitulada Efeitos do real na cena contemporânea, coordenada pela Profa. Maicyra Teles Leão. Contato: maicyraleao@gmail.com.

* Graduanda do Curso de Teatro da Universidade Federal de Sergipe.

** Doutora em Artes Cênicas pela Universidade Federal da Bahia e Professora do Curso de Teatro da Universidade Federal de Sergipe.

*** Graduando do Curso de Teatro da Universidade Federal de Sergipe.
} 
Presente em diferentes esferas e dimensões do cotidiano, o convívio penetra as relações e interações humanas. $O$ termo origina-se do latim convivium, e sua etimologia está relacionada à palavra Banquete que sinonimamente equivale a Festa. Esta definição originalmente se refere aos banquetes e rituais que ocorriam na Europa antiga e com o passar dos séculos foi adquirindo a definição dos dias atuais, tornando-se assim, de modo geral, uma referência da troca e do estar juntos em sociedade ou grupo.

Historicamente, um registro de destaque que descreve tais banquetes encontra-se nas duas principais obras de Homero, llíada e Odisseia.

Estas festividades constituem importante mecanismo de relacionamento entre os membros da aristocracia, pois fazem parte dos ritos de hospitalidade tão presentes no mundo descrito pelo poeta. São nesses banquetes que os aedos executam suas performances e cantam as glórias da aristocracia. (Gabrecht, 2011: 83).

Os banquetes nas epopéias de Homero contam com a participação indispensável do Aedo, também chamado de Bardo, que atuavam cantando, tocando e recitando poesias em locais públicos. Para os líderes cantados nas epopéias, estas figuras eram tão importantes quanto os outros profissionais que contribuíam para o desenvolvimento daquela sociedade ou comunidade. Como o Canto XVII da Odisseia relata:

Conquanto sejas, Antínoo, fidalgo, cortês não falaste; Pois quem teria prazer em chamar alguém de outras paragens, a menos que se tratasse de um desses que aos povos são úteis, áugures, ou carpinteiros, ou médicos para os doentes, ou mesmo aedos divinos, que a todos deleitam com música? Por toda a terra extensíssima os homens somente a estes chamam (apud Gabrecht, 2011: 85 - 86).

Ao analisar a atuação destes personagens das epopéias, o crítico e historiador teatral Jorge Dubatti, em sua obra El Convívio Teatral (2003) destaca o uso da oralidade, ou da literatura oral, nas apresentações dos aedos. Partindo das investigações do teórico francês Florence Dupont, na obra Hòmere et Dallas (1991), ele a coloca como uma característica de 
destaque nestes banquetes, que eram também vistos por Dupont como "um modelo de produção, circulação e recepção literária, vindo em contrapartida com a leitura silenciosa de um livro". Estas palavras expressam também, a importância do convívio ou do encontro para a ocorrência das transmissões orais literárias daquela época.

Partindo desta perspectiva de convívio, Dubatti faz uma aproximação deste para com a arte teatral, quando defende que "o teatro preserva a estrutura do convívio", inicialmente devido à oralidade e ao encontro presencial, que são possíveis nas apresentações teatrais. Em El Convívio Teatral ele acrescenta:

No teatro a letra palpita in vivo, através das formas de produção, circulação e recepção diferentes da letra in vitro, encapsulada, "enfrascada" própria da cultura do livro. A relação de presenciais entre 0 artista e o espectador resguarda e restitui o caráter literário situado espaço-temporalmente na emissão e na recepção, apagando o modo inacabado. (Dubatti, 2003: 15).

Apesar de referir-se diretamente ao Teatro como modalidade na qual o encontro é primordial para o acontecimento e 0 efeito, a colocação de Dubatti estende-se a outras práticas artísticas que lidam com a ação e 0 acontecimento partilhado por presenças, como por exemplo, a performance e a intervenção urbana. Dissolvido entre participação e colaboração, no evento ao vivo, o convívio está configurado como mecanismo de troca permanente entre artista propositor e expectador (Medeiros, 2013). Ainda, também para localizar a estética da performance art, a pesquisadora alemã Érika Fischer-Lichte (2008) chama de feedback looping a esse circuito contínuo de troca motivada pelo convívio. Com isso, além do evento ao vivo, a relação de contaminação entre propositor e expectador (que está na expectativa) não se encerra no evento em si, borrando a fronteira entre processo criativo e acontecimento ao vivo.

Nesse sentido, é possível notar como, cada vez mais, o convívio vem ganhando espaço enquanto investigação processual do procedimento 
criativo. Assim, ele tem se tornado o próprio alvo da elaboração criativa, evidenciando dinâmicas e singularidades de determinadas abordagens.

Retomando Dubatti, ele considera que o fazer teatral (aqui ampliado ao artístico) é formado por três acontecimentos: o convivial, o poiético e a expectação, que são interdependentes, estando sempre conectados. Seguindo nessa mesma perspectiva, Luciana Romagnolli e Mariana Muniz comentam:

O convívio deve estar associado à poiesis, que é o material artístico e sua criação, portanto, necessariamente poiético, ainda que possa ou não ser ficcional, trata-se de um duplo frente à realidade e não necessariamente sua negação. (...) $E$ a essas duas dimensões se soma a expectação: 0 campo de constituição do espaço de percepção do espectador, onde o teatro enfim se constitui como tal, mas não sem os outros dois fatores anteriores. (2014: 252)

Portanto, observa-se que o convívio ao ser percebido ou evidenciado, torna-se um objeto fundamental para o processo criativo (poiesis) que, por conseguinte provocará experiências diretas tanto para o artista quanto para o expectador. Em outras palavras, dentro desta dinâmica, aqui chamada de poiésis convivial, o convívio é pensado como um elemento para construção do conceito, formato de processo criativo, processos de composição, influenciando também na forma de interação e comunicação com 0 expectador.

Ainda sobre as possibilidades das práticas artísticas conviviais, enfatizadas no processo criativo, percebe-se que há uma busca pelo reconhecimento do Outro enquanto alteridade desconhecida. Há um afastamento das inspirações que partem do cotidiano do artista, seja através de situações diárias pessoais ou que abrangem o seu contexto social e cultural, na busca por vivenciar realidades que fogem das suas rotinas em diversos aspectos, de maneira intencional ou ocasional. 
No densamente crítico texto $\mathrm{O}$ artista como etnógrafo, o pesquisador Hal Foster também anuncia esse impulso: "é o Outro cultural e/ou étnico, em nome de quem o artista engajado mais frequentemente luta" (2014: 161).

Para nos aproximar dessa motivação, a seguir, abordaremos alguns aspectos do método etnográfico, na tentativa de elucidar alguns aspectos relevantes para a prática artística.

\section{Alguma etnografia}

Um dos grandes referenciais teóricos da historiografia etnográfica é 0 pesquisador Bronislaw Malinovski, teórico na área antropológica que publicou, no ano de 1922, o estudo Os Argonautas do Pacifico Ocidental. Este livro tornou-se um marco tanto na pesquisa de campo, quanto para a efetivação e demarcação do procedimento etnográfico. Naquele momento, no entanto, ele ainda estava voltado para a compreensão dos povos ditos "nativos", ou que se apresentavam para a civilização como "exóticos", mas atraiu consideráveis mudanças na formulação do conhecimento do Outro. A respeito disso Carolina Chiesa e Letícia Fantinel esclarecem que:

A etnografia é um método de pesquisa surgido na Antropologia em um contexto de crítica ao que se vinha produzindo no seio dessa ciência no século XIX. Nessa época, predominavam os estudos que tinham por objetivo a busca pela reconstituição dos diversos estágios da evolução humana através, principalmente, do estudo de povos ditos "primitivos". (2014: 02).

Com a criação do método etnográfico, a postura dos pesquisadores que diziam estar em campo modificou-se. Especialmente, transformou-se a figura do pesquisador, isolado em seu gabinete, descrevendo outras culturas apenas com recursos advindos de embasamento teórico, pautado consequentemente numa visão de mundo particularizada e não na convivência. Estar em campo, por outro lado, passou a exigir do pesquisador, determinadas qualidades de presença e troca nas quais 0 convívio passou a ser determinante para a formulação do conhecimento. 
O convívio com os nativos e a polifonia possibilitada através da interlocução com os integrantes dos grupos estudados possibilitou mudanças basilares na ciência antropológica, que deixa de ser centrada na sociedade do pesquisador e passa a ser relativizada mediante a própria visão de mundo dos nativos. (Chiesa; Fantinel, 2014: 02).

Esse deslocar-se de seus próprios referenciais, na antropologia, ampliouse para situações mais complexas das sociedades, diversificando ramos da antropologia e ampliando as fronteiras da própria disciplina científica. Mais uma vez evidencia-se essa busca por alteridades, não mais baseada em verticalidades de ordem econômica ou tecnológica, mas em termos de reconhecimento de uma diversidade definida a partir de sua identidade cultural. Essa discussão é também problematizada por Foster e será retomada adiante. Por hora, interessa-nos perceber esse tipo de impulso advindo do meio artístico.

\section{Olhar Forasteiro}

Olhar Forasteiro integrou o Prêmio Funarte de Teatro Myriam Muniz, 2008, e foi realizado em 9 cidades do interior do estado de Goiás, incluindo sua capital Goiânia e a cidade de Planaltina, no Distrito Federal. O projeto consistia na criação e apresentação de cenas criadas a partir do compartilhamento de narrativas coletadas por sua vez, através da errância das três atrizes, Camila Guerra, Lucianna Mauren e Maicyra Leão, por ruas das cidades.

A partir de três figuras, as três Marias, uma caixeira viajante, uma cigana e uma curandeira, as atrizes percorriam ruas das cidades do interior de Goiás relacionando-se com os habitantes e convivendo com estes por um período de três dias. Esse convívio fomentava trocas e apreensão de narrativas para que, no terceiro dia, uma encenação fosse apresentada na praça pública da cidade. 0 tipo de contato estabelecido com esses transeuntes e habitantes era travado a partir de conversações lúdicas e simbólicas, já que elas se propunham a um contato direto, de um para um, disposto a encontrar lugares afetivos latentes. 


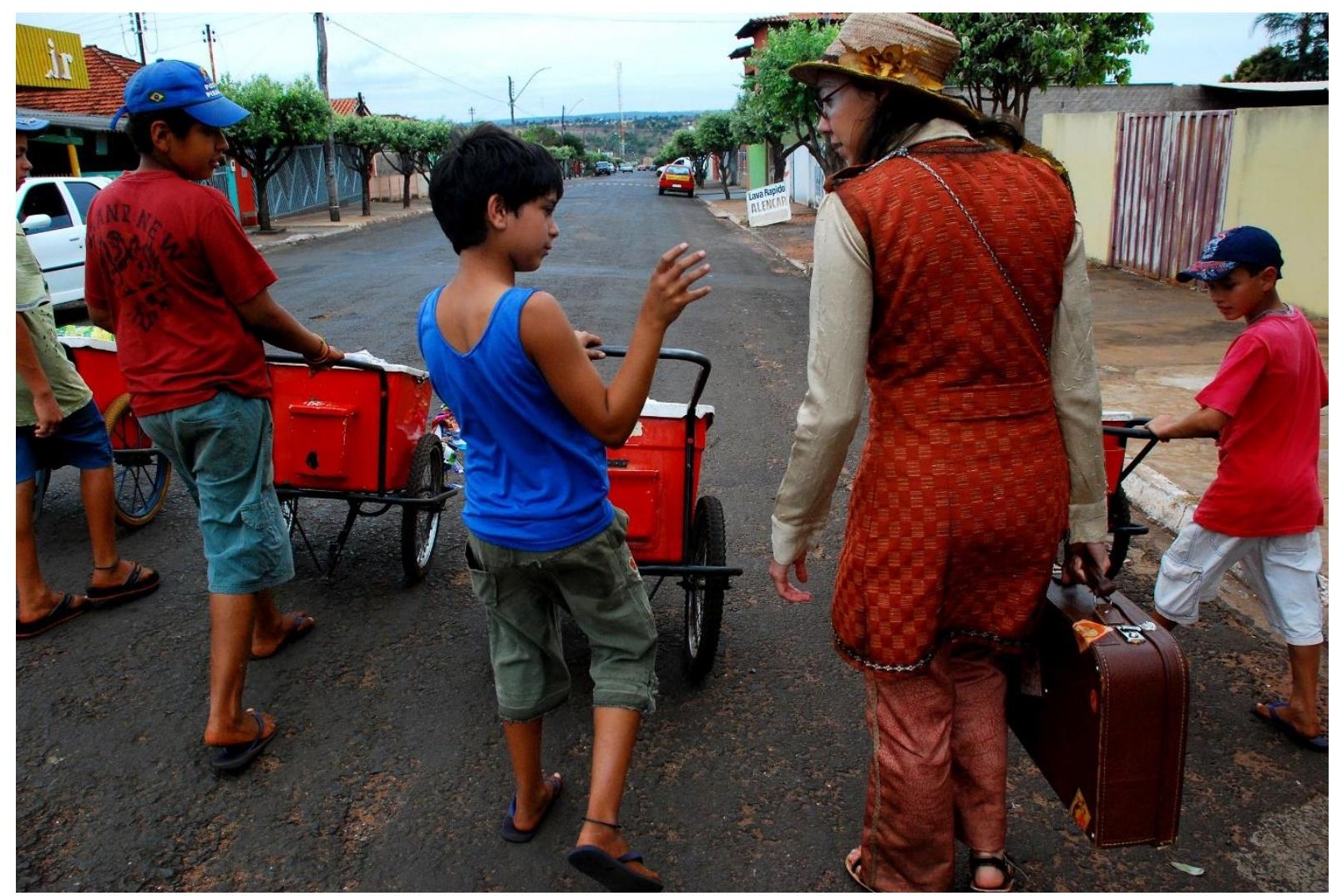

Fig.1. Olhar Forasteiro, 2009, Itajá-GO. Foto: Andres Rodrigues

Assim descrito, percebemos como a noção de convívio é adotada pelo projeto não apenas de forma intrínseca ao compartihamento enquanto evento, mas como própria motivação criativa e motivo de ser do espetáculo apresentado ao terceiro dia. Nesse sentido, o convívio é encarado como a poiesis do próprio projeto, de acordo com a distinção proposta por Dubatti e apresentada anteriormente.

\section{Aproximando}

A latência prevista por esse contato efêmero e fugidio, forasteiro, proposta no projeto Olhar Forasteiro, designa uma proposição conceitual que se apropria, mas diferencia-se, do princípio de trabalho de campo proposto pela etnografia. Especificamente, se considerarmos os diários de campo desenvolvidos nas saídas antropológicas notamos como o registro gráfico, 
tornado público em Olhar Forasteiro via um blog virtual (http://olharforasteiro.blogspot.com.br/), torna-se uma necessidade para 0 acompanhamento da percepção, mas demanda diferenciações quanto às finalidades propostas.

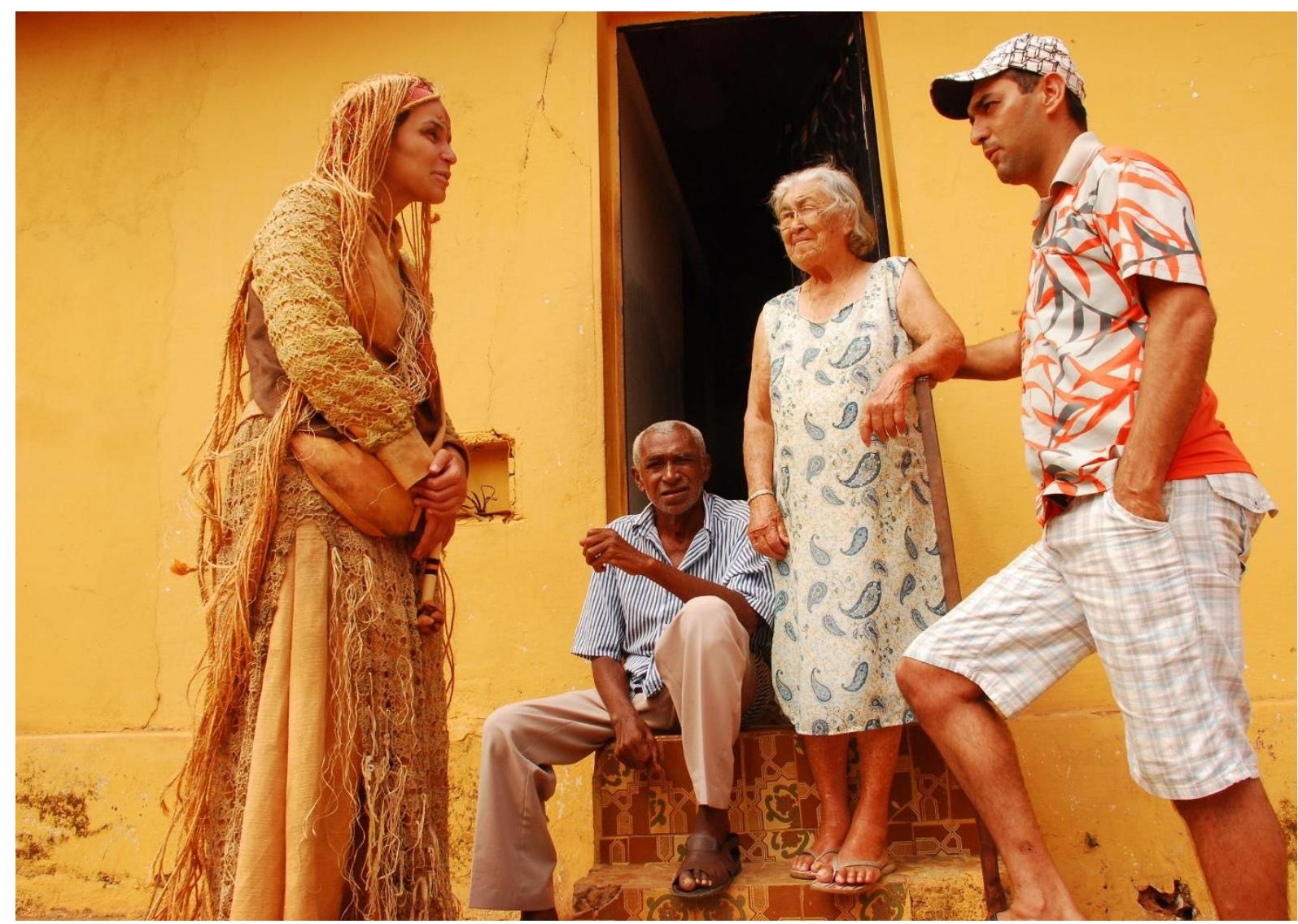

Fig.2. Olhar Forasteiro, 2009, Planaltina-DF. Foto: Andres Rodrigues

Como as próprias propositoras sugerem no blog: "É um encontro rápido e fugaz que busca na qualidade da observação e interação, a possível generosidade e intensidade do olhar artístico sobre a própria vida e 0 cotidiano." Com isso, a descrição desse contato e compartilhamento de narrativas e impressões se dá a partir de uma construção poética e também descritiva, com o intuito de transformá-las posteriormente em texto teatral. 
No entanto, ainda assim, embutido neste modo de registro, há um interesse na compressão do contexto social daquela localidade, tornando a observação fator determinante dessa aproximação.

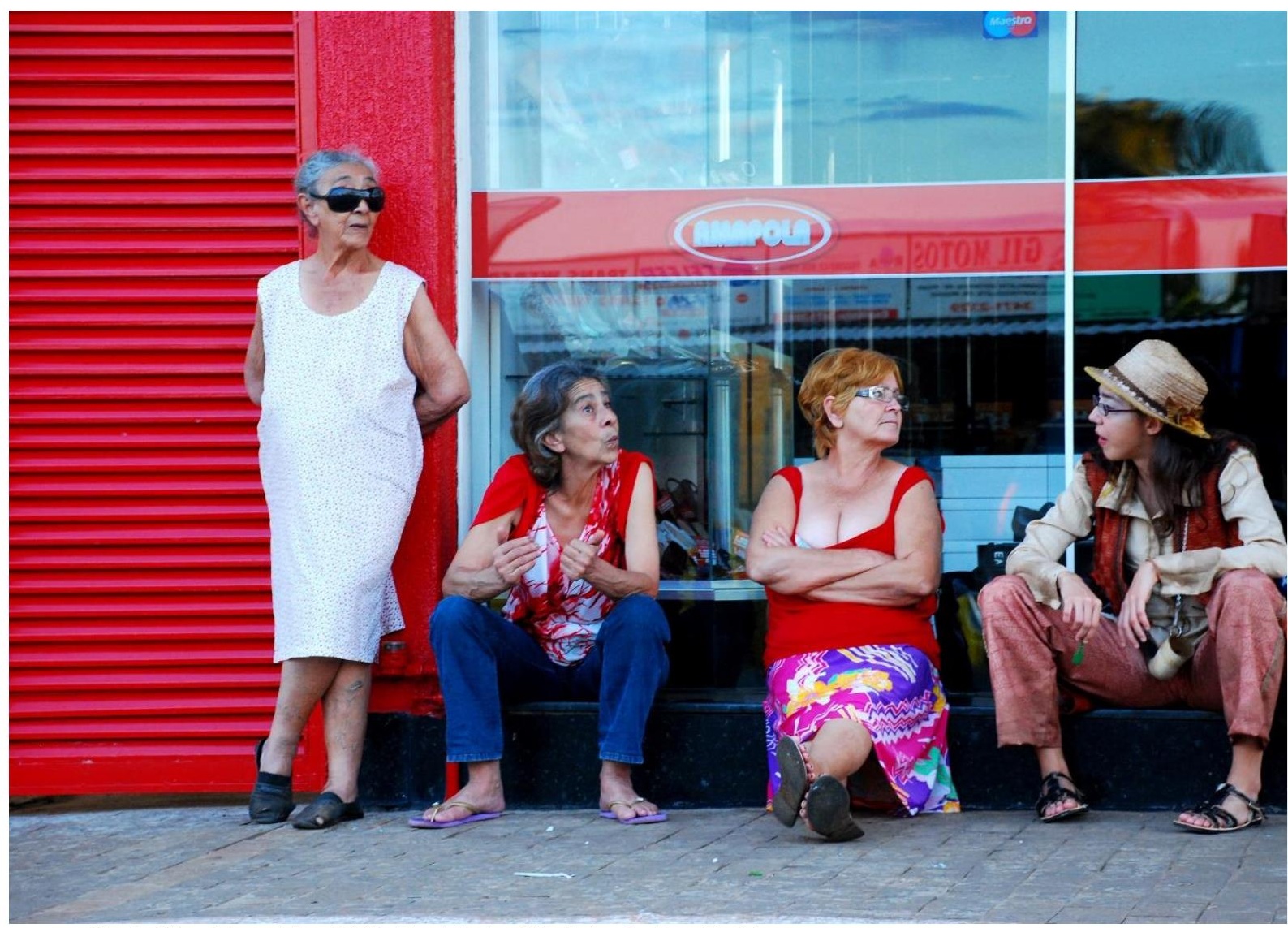

Fig.3. Olhar Forasteiro, 2009, Pontalinda-GO. Foto: Andres Rodrigues

De forma consonante, a pesquisa etnográfica começa "com observações descritivas gerais, numa tentativa de traçar um panorama da situação social e do que ocorre ali" (Neves, 2006: 07). A pesquisadora Vanessa Neves ainda acrescenta: "O processo de descobertas é sempre dialético e paradoxal: estranhar o que está se tornando familiar, familiarizar-se com 0 que se torna mais uma vez estranho. Então, há neste momento, a possibilidade de novos re-conhecimentos: algo de novo pode ser produzido." (idem). Se considerarmos o estranhamento na formulação dessas impressões, a própria condição do projeto Olhar Forasteiro denota a manutenção desse estranhamento já que ocorre de forma fulgaz. 
Ainda, sobre estas aproximações é importante destacar a técnica denominada observação direta, existente na pesquisa etnográfica:

A observação direta é sem dúvida a técnica privilegiada para investigar os saberes e as práticas na vida social e reconhecer as ações e representações coletivas na vida humana. É se engajar em uma experiência de percepções em contrastes sociais, culturais, e históricos. As primeiras inserções no universo de pesquisa conhecidas como "saídas exploratórias", são norteadas pelo olhar atento ao contexto e a tudo que acontece no espaço observado. (Rocha; Eckert, 2008: 02).

De forma genérica, pode-se considerar que toda ida a campo envolve observação direta. No entanto, há esferas de observação compreendidas também como participantes que diferenciam o locus de onde é estabelecida a observação. Enquanto trabalho etnográfico, essa participação pode envolver um convívio social íntimo, fazendo com que o pesquisador penetre as vias de constituição cultural, diluindo-se no contexto. No caso da proposição artística, em questão, há uma clara definição quanto à posição do observador. Apesar de "invadirem" o cotidiano local e mesmo esferas particulares, como casas, é possível perceber que aquelas figuras, as Marias, estão destacadas da realidade enquanto personificações. Esse destacamento dificulta a camuflagem do ato artístico.

Com relação à fusão entre poiesis e realidade, em 0 artista como etnográfo, Foster problematiza exatamente essa questão. Ao se portar como um investigador sócio-cultural de determinada exterioridade e se apropriar de dados desse real, o artista está ameaçado a primitivizar as relações por conta do fetiche pelo Outro dotado de dado "verdadeiro".

A fantasia primitivista é absorvida pelo pressuposto realista, de modo que, agora, considera-se que o Outro está dans le vrai (no verdadeiro). Essa versão primitivista do pressuposto realista, esse lugar da verdade política em um Outro ou um fora projetados, tem efeitos problemáticos que vão além da codificação automática da identidade vis-à-vis a alteridade aqui apontada. Primeiramente, este fora não é o Outro em nenhum sentido simples. Além disso, esse lugar da política como o fora e o Outro, como uma oposição transcendental, pode desviar o foco de uma política do aqui e agora, da contestação imanente. (Foster, 2014: 164-165). 
Apesar da discussão sobre o efeito político não ser o objetivo deste texto, o que vale ressaltar é que Foster propõe que é preciso manter em vigilância o tipo de abordagem que se faz desse Outro. 0 acordo tácito de troca está claro a partir do convívio? O que é gerado a partir desse convívio, seja do ponto de vista etnográfico ou artístico, e como é compartilhado? Como escapar à essa fantasia primitivista arraigada no interesse pelo Outro? São questões que certamente não serão respondidas aqui, mas que merecem visibilidade nesse atravessamento entre arte e etnografia.

Para concluir, é importante ressaltar que o projeto Olhar Forasteiro não tem a intenção de se denominar como uma pesquisa etnográfica. Da mesma forma, este artigo não pretende afirmar que elas (as atrizes) "quando viram haviam feito uma etnografia acidental", como intitulam seu artigo Chiesa e Fantinel.

Nesse sentido, vale a pena trazer à tona uma discussão proposta pela antropóloga Mariza Gomes e Souza Peirano, que situa a etnografia como prática intrínseca à formulação empírica, negando veementemente a etnografia enquanto método:

Como todos sabemos, a etnografia é a ideia-mãe da antropologia, ou seja não há antropologia sem pesquisa empírica. A empiria - eventos, acontecimentos, palavras, textos, cheiros, sabores, tudo que nos afeta os sentidos -, é o material que analisamos e que, para nós, não são apenas dados coletados, mas questionamentos, fonte de renovação. Não são "fatos sociais", mas "fatos etnográficos", como nos alertou Evans Pritchard em 1950. (Peirano, 2014: 380).

Estes fatos vagam em meio à empiria nos diversos grupos sociais e se evidenciam quando são destacados, ou melhor dizendo, quando são estranhados. "Tudo que estranhamos nos leva a refletir e a imediatamente nos conectar com outras situações semelhantes que conhecemos ou vivemos (ou mesmo opostas), e a nos alertar para o fato de que muitas vezes a vida repete a teoria." (idem: 378 ). 
No entanto, só estranhar não é o suficiente para se ter um objeto de estudo etnográfico. $O$ confronto com o Outro, com a alteridade desconhecida, deve sugerir desdobramentos teóricos e reflexivos, no sentido de despertar um conhecimento crítico. Assim, "monografias não são resultado simplesmente de 'métodos etnográficos'; elas são formulações teórico-etnográficas." (idem: 383).

À luz do procedimento etnográfico, proposições artísticas se potencializam enquanto possibilidade de conjunção para o reconhecimento histórico, geográfico, sócio-cultural, uma vez que o convívio e sua disponibilidade quanto poiesis de criação viabilizam brechas no extrato social. De certo modo, sob a chancela de arte, a penetração pelas vias da observação (e feedback looping) do Outro favorecem o florescimento de formulações teórico- artísticas-etnográficas, como propõe Peirano, reafirmando que essa transversalidade corre riscos, como apontou Foster, mas também convoca meios.

\section{Referências}

CHIESA, Carolina.; FANTINEL, Letícia. "Quando eu vi, eu tinha feito uma etnografia": notas sobre como não fazer uma "etnografia acidental". IN: VIII Encontro de Estudos Organizacionais da ANPAD. Gramado/RS, 2014.

DUBATTI, Jorge. Teatro, encuentro de presencias - Análisis de las estructuras conviviales como contribución a la teatrologia. In: El convivio teatral - Teoría y Práctica del Teatro Comparado. Buenos Aires: Atuel, 2003.

FISCHER-LICHTE, Erika. The transformative power of Performance: a new aesthetics. London: Routledge. 2008.

FOSTER, Hal. O retorno do real: a vanguarda no final do século XX. SãoPaulo: Cosac Naify, 2014.

GABRECHT, Ana. A Atuação do Aedo nos Banquetes Homéricos. In: Revista Caminhos da História. Vassouras, v. 7, n. 1, p. 69-92, jan.jjun., 2011.

MEDEIROS, Maria Beatriz de. Composição Urbana: surpreensão e fuleragem. In: Palco Giratório: circuito nacional. Rio de Janeiro: SESC, Departamento Nacional, 2013.

NETTO, Maria Amélia Gimmler. Ética, Boniteza e Convívio Teatral entre Grupos e Comunidades. IN: Revista do Programa de Pós Graduação em Artes Cênicas PPGAC. Porto Alegre: UFRGS, 2010. 
NEVES, Vanessa Ferraz Almeida. Pesquisa-ação e Etnografia: Caminhos Cruzados. In: Revista Pesquisas e Práticas Psicossociais, v. 1, n. 1, São João delRei, jun.2006.

PEIRANO, Mariza. Etnografia não é Método. In: Horizontes Antropológicos, Porto Alegre, Vol. 20, n. 42, p. 377-391, jul./dez. 2014.

ROCHA, Ana; ECKERT, Cornelia. Etnografia saberes e práticas. In: Ciências Humanas: pesquisa e métodos. Porto Alegre: Editora da Universidade, 2008.

ROMAGNOLLI, Luciana Eastwood; MUNIZ, Mariana de Lima. Teatro como acontecimento convival: uma entrevista com Jorge Dubatti. In: Revista Urdimento. Florianópolis v.2, n.23, p 251-261, dezembro 2014.

Artigo recebido em fevereiro de 2016. Aprovado em maio de 2016 